\title{
Personagens negras nos liuros de imagens do Programa Nacional Biblioteca da Escola (PNBE) para a Educação Infantil
}

\author{
Black characters in the wordless picturebooks of the Programa \\ Nacional Biblioteca da Escola (PNBE) for Children's Education
}

\section{Personas negras en los libros de imágenes del Programa Nacional Biblioteca da Escola (PNBE) para la Educación Infantil}

\author{
Maria Laura Pozzobon Spengler ${ }^{1}$ \\ Instituto Federal Catarinense, Campus Blumenau, Professora do Curso de Pedagogia \\ Eliane Santana Dias Debus ${ }^{2}$
}

Universidade Federal de Santa Catarina, Departamento de Metodologia de Ensino, Programa de Pós-Graduação em Educação do Centro de Ciências da Educação, Professora

Resumo: 0 artigo busca evidenciar as personagens negras nos livros de imagem do acervo do Programa Nacional Biblioteca da Escola (PNBE) para a Educação Infantil nas suas quatro edições (2008, 2010, 2012, 2014). Para tal, realizou-se o mapeamento dos títulos, 77 no total, divulgados pelo Ministério da Educação/Centro de Alfabetização Leitura e Escrita (MEC/CEALE), considerando 59, pois alguns continham pequenas narrativas e palavras-chave. Desse total, foram analisados 13 títulos, dos quais cinco trazem personagens negras que estão inseridas no contexto da narrativa com outras personagens, mas sem participação ativa, e oito trazem personagens negras que participam da narrativa. Desses oito, em quatro as personagens negras são protagonistas, a saber: Bem me quero, bem me querem (RENNÓ, 2009a), 0 almoço (VALE, 1987), Mar de sonhos (NOLAN, 2012) e Quando os tamtans fazem tum-tum (ZIGG, 2013). A partir do referencial teórico sobre o livro de imagem (BELMRR, 2017; SPENGLER, 2017) em diálogo com os estudos sobre literatura infantil e a cultura africana e afro-brasileira (ARAUJO, 2015; DEBUS, 2017, REYES, 2010), a análise busca evidenciar qual a representação proposta por essas narrativas e suas contribuições, ou não, para a Educação das Relações Étnico-Raciais (ERER). Palavras-chave: Livro de imagem. Literatura para a infância. Relações étnico-raciais.

Abstract: The article seeks to highlight the black characters in the wordless picturebooks of the collection of the Programa Nacional Biblioteca da Escola (PNBE) for Child Education in its four editions

Doutora em Educação pela Universidade Federal de Santa Catarina; Mestre em Ciências da Linguagem pela Universidade do Sul de Santa Catarina; http://orcid.org/0000-0002-9361-2051; ttp://lattes.cnpq.br/7678316649787689.

2 Doutora em Teoria da Literatura pela Pontifícia Universidade Católica do Rio Grande do Sul; Mestre em Literatura pela Universidade Federal de Santa Catarina; http://orcid.org/0000-0003-0555-2069; http://lattes.cnpq.br/8529733083684329. 
(2008, 2010, 2012, 2014). For this purpose, the mapping of the titles was carried out, 77 in total, published by MEC/CEALE, recital 59 (since some contained small narratives and keywords). Of the total of 59, we analyzed 13 titles, five of which include black characters that are inserted in the context of the narrative with other characters, but without active participation and eight with black characters that participate in the narrative. Of these eight, four black characters are protagonists in Bem me quero, bem me querem (RENNÓ, 2009a), 0 almoço (VALE, 1987), Mar de Sonhos (NOLAN, 2012) and Quando os tam-tans fazem tum-tum (ZIGG, 2013). Based on the theoretical reference on the wordless picture books (BELMIRO, 2017; SPENGLER, 2017) in dialogue with the studies on children's literature and African and Afro-Brazilian culture (ARAUJO, 2015; DEBUS, 2017, REYES, 2010), the analysis seeks to highlight the representation proposed by these narratives and their contributions, or not, to the education of ethnic relations (ERER). Keywords: Wordless picture books. Literature for children. Ethnic relations.

Resumen: El artículo busca evidenciar a los personajes negros en los libros de imagen del acervo del Programa Nacional Biblioteca da Escola (PNBE) para la Educación Infantil en sus cuatro ediciones (2008, 2010, 2012, 2014). Para ello se realizó el mapeo de los títulos, 77 en total, divulgados por el MEC/CEALE, considerando 59 (ya que algunos contenían pequeñas narrativas y palabras clave). Del total de 59 , analizamos 13 títulos, cinco que traen personajes negros que se insertan en el contexto de la narrativa con otros personajes, pero sin participación activa y ocho traen personajes negros que participan en la narrativa. De estos ocho, cuatro los personajes negros son protagonistas en Bem me quero, bem me querem (RENNÓ, 2009a), 0 almoço (VALE, 1987), Mar de sonhos (NOLAN, 2012) y Quando os tam-tans fazem tum-tum (ZIGG, 2013). A partir del referencial teórico sobre el libro de imagen (BELMIRO, 2017; SPENGLER, 2017) en diálogo con los estudios sobre literatura infantil y la cultura africana y afro-brasileña ARAUJO, 2015; DEBUS, 2017, REYES, 2010), el análisis busca evidenciar cuál es la representación propuesta por esas narrativas y sus contribuciones, o no, a la educación de las relaciones étnicas (ERER).

Palabras clave: Libro de imagen. Literatura para la infancia. Relaciones étnicas.

Recebido em 25 de setembro de 2017 Aceito em 26 de outubro de 2018 Publicado em 19 de fevereiro de 2019

\section{INTRODUÇÃO}

As escolhas dos temas de pesquisas geralmente recaem sobre os nossos desejos em diálogo com a sua relevância. Assim, ao nos debruçarmos sobre os livros literários para pequena infância que apresentam personagens negras, recorremos àqueles que fazem parte do acervo das instituições de Educação Infantil, enviados pelo Programa Nacional Biblioteca da Escola (PNBE) nos anos de 2008, 2010, 2012 e 2014, particularmente os 
livros de imagens. Cientes de que os acervos foram distribuídos para todas as instituições brasileiras, acreditamos que os livros sejam de fácil acesso aos professores e às crianças e que, ao refletirmos sobre eles, possamos contribuir para relativizar o seu uso a partir do conhecimento de sua contribuição, ou não, para a educação das relações étnico-raciais.

0 PNBE entrou em vigor no Brasil em 28 de abril de 1997, por meio da Portaria Ministerial n. 584, com o intuito de promover a leitura e o acesso ao conhecimento, fomentando o contato da comunidade escolar com o livro (BRASIL, 1997). 0 Programa selecionou, adquiriu e distribuiu, por meio de recursos do Fundo Nacional de Desenvolvimento da Educação (FNDE), em parceria com a Secretaria de Educação Básica do Ministério da Educação (SEB/MEC), livros literários, bem como obras teóricas de referência para as instituições de Educação Básica de todo o País (FERNANDES, 2007). Desse modo, com o objetivo primordial de democratizar o acesso ao livro literário, também fomentou esforços para distribuir materiais de pesquisa e de referência aos professores. 0 PNBE foi suspenso no ano 2015, por conta da crise política e econômica no Brasil, que colocou por terra os encaminhamentos em prol de um país leitor.

Como principal política pública de leitura da história do País, durante os 17 anos em que o Programa vigorou, percebeu-se uma ampliação e aprimoramento ao triplicar, de 1998 a 2014, o investimento financeiro na compra de acervo para as bibliotecas escolares, conforme é possivel perceber na Tabela 1 .

Tabela 1 - Investimento financeiro PNBE - 1997 a 2014

\begin{tabular}{ccc}
\hline \multirow{2}{*}{ Investimento total - R\$ } & 1997 & 2014 \\
\cline { 2 - 3 } & $\mathrm{R} \$ 29.830 .886,00$ & $\mathrm{R} \$ 84.075 .541,40$ \\
\hline
\end{tabular}

Fonte: Spengler (2017).

De forma progressiva mais instituições foram atendidas, e a quantidade de livros distribuída foi ampliada em mais de cinco vezes, como pode ser percebido na Tabela 2.

Tabela 2 - Dados numéricos de distribuição do PNBE - 1997 a 2014

\begin{tabular}{ccc}
\hline & 1997 & 2014 \\
\hline Instituições atendidas & 20.000 & 253.520 \\
Livros distribuidos & 3.660 .000 & 19.394 .015 \\
\hline
\end{tabular}

Fonte: Spengler (2017).

Estabelecendo parcerias com instituições e universidades, de 2005 a 2015, o Centro de Alfabetização, Leitura e escrita (CEALE), grupo de pesquisa ligado à Faculdade de Educação da Universidade Federal de Minas Gerais (UFMG), foi responsável pela seleção dos títulos 
literários, por meio de um trabalho de pesquisa que aconteceu de forma descentralizada, já que envolveu pesquisadores de diferentes estados brasileiros, possibilitando, assim, que nos mais diferentes contextos brasileiros seja possível discutir sobre as escolhas dos livros que os representem, já que esses livros circularão em diferentes instituições educacionais de todo o País.

Os acervos para as diferentes etapas de ensino de instituições públicas do País foram compostos por diferentes gêneros literários, divididos em quatro categorias: textos em verso (poemas, quadras, parlendas, cantigas, trava-lingua, adivinhas); texto em prosa (pequenas histórias, novelas, contos, crônicas, textos de dramaturgia, memórias, biografias); livros de imagens e livros de histórias em quadrinhos (dentre os quais se incluem obras clássicas da literatura universal, artisticamente adaptadas ao público da Educação Básica). As obras foram escolhidas a partir dos seguintes critérios, elencados por Paiva (2012, p. 15, grifo do autor):

\footnotetext{
A qualidade textual, que se revela nos aspectos éticos, estéticos e literários, na estruturação narrativa, poética ou imagética, numa escolha vocabular, que não só respeite, mas também amplie o repertório linguistico dos leitores da faixa etária correspondente a cada uma das edições do programa; qualidade temática, que se manifesta na diversidade e adequação dos temas, e no atendimento aos interesses dos leitores, aos diferentes contextos sociais e culturais em que vivem e ao nivel dos conhecimentos prévios que possuem; qualidade gráfica que se traduz na excelência de um projeto gráfico capaz de motivar e enriquecer a interação do leitor com - livro e na qualidade estética das ilustrações; e articulação entre texto e ilustrações e o uso dos recursos gráficos adequados aos leitores.
}

Atuando em todas as etapas da educação básica, somente a partir do ano 2008 as instituições de Educação Infantil passaram a ser também atendidas pelo Programa, recebendo bianualmente quatro acervos até o ano 2014, que somaram um total de 360 livros literários. Desse acervo, nosso olhar repousa sobre os livros de imagem que, segundo divulgação do MEC e Ceale, totalizam 77 títulos. No entanto, ao avaliarmos os títulos, constatamos que 18 continham pequenas narrativas e palavras-chave e, assim, os desconsideramos, resultando em 59 títulos cuja composição é uma narrativa exclusivamente por imagens. A partir disso, destacamos 13 livros que trazem personagens negras na constituição da narrativa. Destes, cinco livros trazem personagens que estão inseridos no coletivo, algumas apresentadas de forma aligeirada; outros oito livros trazem personagens negras que participam da narrativa, dos quais quatro apresentam a personagem negra como protagonista, a saber: Bem me quero, bem me querem (RENNÓ, 2009a), 0 almoço (VALE, 1987), Mar de sonhos (NOLAN, 2012) e Quando os tam-tans fazem tum-tum (ZIGG, 2013). Desse modo, serão foco de nossa leitura 13 livros, com olhar mais detido nos quatro que apresentam o protagonismo. 


\section{LIURO DE IMAGEM E O CONTEXTO DAS RELAÇÕES ÉTNICO- RACIAIS}

Os livros de imagem fazem parte da composição dos acervos literários para todos os níveis de ensino atendidos pelo PNBE; essa presença comprova a existência de uma preocupação sobre a leitura das diferentes linguagens contemporâneas presentes no mundo, em especial, as imagens.

0 livro de imagem é concebido como aquele que conta uma história sem que haja a necessidade de expressá-la por meio da linguagem verbal escrita, sendo as imagens organizadas sucessivamente, cada uma delas interligada por meio de um fio narrativo. Dessa forma, o livro de imagem é literário porque traz em sua composição todos os elementos que the garantem a literariedade, como enredo, personagens e espaço.

Para Belmiro (2017, p. 1), o livro de imagem pode ser chamado de narrativa visual, já que é um:

[...] livro com imagens em sequência e que conta uma história, geralmente selecionando uma situação, um enredo e poucos personagens. Constitui-se como uma narrativa visual, que aproxima duas condições básicas para sua realização: a dimensão temporal (sequência linear das imagens) e a dimensão espacial la lógica de organização espacial dos elementos que compõem as imagens).

Nos acervos destinados para a Educação Infantil, os livros de imagem estão bem representados numericamente, já que são 59 em um total de 360 títulos. Isso ocorre porque o livro de imagem traz em si uma proposta de autonomia de leitura, já que mesmo as crianças menores conseguem, de forma bastante singular, realizar a leitura das imagens. Para Abramovich (1997, p. 33), essas narrativas instigam a fantasia e são dotadas de conhecimento, pois são "experiências de olhar [...] De um olhar múltiplo, pois se vê com os olhos do autor e do olhador/leitor, ambos enxergando o mundo e as personagens de modo diferente, conforme percebem esse mundo [...]"

A pesquisadora Reyes (2010) destaca a importância da leitura dos livros de imagem, especialmente para as crianças pequenas, pois os livros ampliam o vocabulário e o desenvolvimento motor, bem como noções de lateralidade, quando desvendadas a técnica de folhear as páginas, a descoberta do espaço gráfico e a curiosidade com o funcionamento dos mecanismos da linguagem. A riqueza da possibilidade narrativa de um livro dá a cada um deles características que os tornam singulares. lsso posto, podemos afirmar que a representação 
imagética nesses livros possibilita que a criança possa, além de se reconhecer, ampliar seu repertório de conhecimento de mundo, e isso diz respeito também à diversidade apresentada.

A Lei n. 10.639/2003, que instituiu a obrigatoriedade do ensino da história e da cultura africana e afro-brasileira (BRASIL, 2003), e a Lei n. 11.645/2008, que introduz a obrigatoriedade do ensino da história e da cultura africana e afro-brasileira e indígena (BRASIL, 2008), colaboraram, por certo, para a ampliação dos títulos de livros para infância no mercado editorial, o que não pode ser analisado sem problematização, pois o mercado, inserido no contexto capitalista, busca o lucro ao trazer em suas publicações temáticas que são emergentes dentro de um contexto educacional: assim foi com os temas transversais, a partir dos Parâmetros Curriculares Nacionais (PCN), instituídos pela Lei de Diretrizes e Bases (LDB) em 1996 (BRASIL, 1996).

Algumas pesquisas têm se debruçado sobre o acervo do PNBE e a temática étnicoracial. Desse modo, sem a pretensão de realizar um estado do conhecimento, elencamos algumas pesquisas, que são resultados de dissertações de mestrado e teses de doutorado, que focalizam a temática étnico-racial no acervo do PNBE nos Anos Iniciais do Ensino Fundamental. Destacamos, então, dois grupos, como indicado por Debus (2017, p. 44-45):

\footnotetext{
[...] o primeiro que estuda o acervo da educação infantil, como as pesquisas de Verediane Cintia de S. Oliveira (2010) que focaliza o acervo de 2008. 0 segundo sobre os acervos para os anos iniciais do ensino fundamental como as pesquisas de Leda C. da Silva Ferreira (2008) focalizando os aspectos da pluralidade etária, social, étnica e de gênero nos 300 títulos do acervo do PNBE/2005; de Ana Carolina Venâncio (2009) que analisa 20 títulos do acervo do PNBE/2008; Débora C. de Araujo $(2010,2015)$ que se debruça sobre a política do PNBE e seus encaminhamentos para inserção da temática africana e afro-brasileira nos livros desse acervo e os estudos de Naiane R. Lopes (2012) que realizam análise sobre o acervo do PNBE/2010 e buscam verificar como os estudantes dos ensino fundamental I percebem a presença da personagem negra na literatura infantil.
}

Nosso intento, neste texto, é focalizar na particularidade do livro de imagem, acreditando que esse gênero, pela sua dimensão estético-criativa e pela especificidade de não trazer a palavra escrita, e também como o livro que dialoga palavra e ilustração, dimensiona as relações étnico-raciais. Nosso olhar recai, inicialmente, para a estrutura material do livro (paratextos) e, a seguir, o foco narrativo e a representação das personagens por meio das imagens, pois elas podem servir como um meio para cristalizar as percepções acerca do mundo. 


\section{AS PERSONAGENS NEGRAS INSERIDAS NO CONTEXTO DAS NARRATIUAS}

Em cinco títulos as personagens negras estão inseridas no contexto narrativo, mas não exercem papel ativo, aparecem de forma aligeirada e sem ação, são eles: 0 presente que veio do céu, Lá vem o homem do saco e Voa pipa, voa, os três títulos de autoria de Regina Rennó, 0 Encontro, de Michele lacocca, e 0 gato e a menina, de Sonia Junqueira.

0 presente que veio do céu, livro de Regina Rennó (2007), tem o formato quadrado, de $21 \mathrm{~cm} \times 21 \mathrm{~cm}$ (Figura 1). Com ilustrações de aspecto realista, a narrativa apresenta como protagonista um menino branco que constrói um paraquedas usando brinquedos como matéria-prima. 0 paraquedas é arremessado pela janela do apartamento em que o menino mora, e as imagens seguintes mostram outras janelas pelas quais o brinquedo passa em sua descida no ar, a casa de uma senhora sentada tricotando, depois pela janela do apartamento de um menino negro vestindo pijamas que o observa (RENNÓ, 2007, p. 12). Quando amanhece, o paraquedas passa por uma janela de uma família que, sentada à mesa, toma café da manhã. Por fim, chega mais perto da cidade nas mãos de um menino de rua que está cercado de crianças indo à escola. A narrativa está composta de 18 imagens, sendo 17 em páginas simples e uma que ocupa todo o espaço de uma página dupla logo após as páginas centrais da narrativa, todas elas dispostas dentro de uma margem. A noção de passagem de tempo e movimento vai sendo construída a partir da visualização do objeto de diferentes pontos de vista, em diferentes espaços.

Constata-se nas ilustrações que as personagens são representadas diversificadamente quanto à faixa etária, gênero, classe social e etnia; a personagem negra aparece nesse contexto somente uma vez no decorrer da história, em apenas uma das páginas da narrativa (Figura 1). 
Figura 1 - Capa e miolo do livro 0 presente que veio do céu
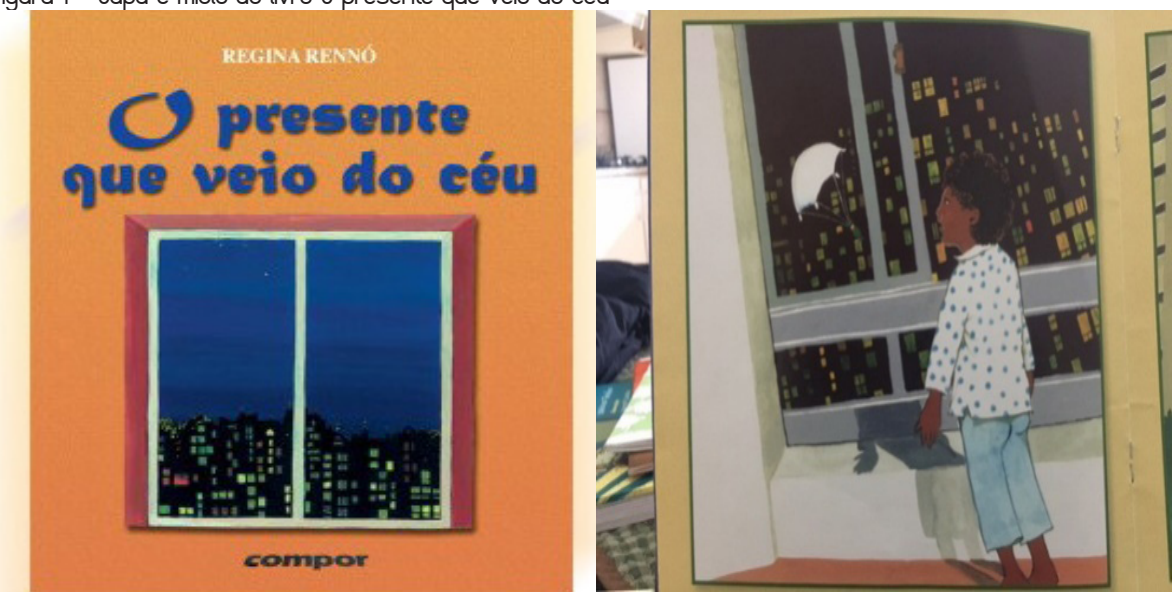

Fonte: os autores.

0 livro 0 Encontro, de Michele lacocca (2008), tem 24 páginas e é quadrado, medindo $23,8 \mathrm{~cm}$ X 23,8 cm. A narrativa possui 11 imagens que apresentam desenhos com traços animados e ocupam o espaço de páginas duplas. 0 livro conta a história de um cachorro bastante ansioso que corre apressado pelos cômodos da casa, mas que só é conhecido nas páginas finais da narrativa. A velocidade de sua corrida é marcada em cada uma das cenas pelo movimento da passagem: no quintal, quando as roupas penduradas no varal se movimentam; na cozinha, quando encontra uma mulher cozinhando ou quando as cadeiras são deslocadas de posição; na sala, quando passa embaixo de uma mesa e assusta o gato e também uma senhora que tricotava, que dá um salto de sua cadeira de balanço; ou com um bebê, que faz festa dentro do berço quando percebe o movimento. Uma menina tenta segurar com as mãos o que se movimenta depressa, e até as fotografias penduradas na parede da sala onde um senhor lia o jornal seguem o movimento com os olhos, bem como um homem que entra pela porta de casa com uma maleta na mão. Um único menino negro faz parte da narrativa, em meio à multidão que está na calçada, nas páginas finais da história. $\mathrm{A}$ narrativa finaliza quando o cachorro encontra o menino que esperava (Figura 2). 
Figura 2 - Capa e miolo do livro 0 encontro

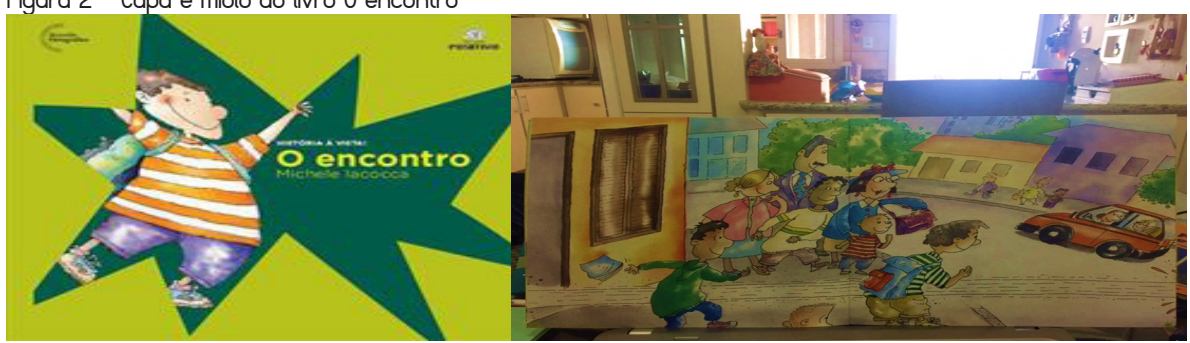

Fonte: os autores.

Esse livro, assim como os próximos dois que serão descritos, apresenta essas personagens sem nenhuma espécie de protagonismo, apenas inserindo-as em grupos. Isso demonstra uma preocupação em mostrá-las em atividades cotidianas, e mesmo sem o protagonismo, ainda podemos afirmar que há, sim, o cuidado com a representatividade étnica nas narrativas.

O gato e a menina é o livro de Sonia Junqueira, com ilustrações de Mariângela Haddad (JUNQUEIRA; HADDAD, 2012). Tem formato retangular vertical de $21 \mathrm{~cm} \mathrm{X} 24 \mathrm{~cm}$. As imagens, com características animadas, estão dispostas de diferentes formas no decorrer das páginas, em alguns momentos organizadas como imagens de uma história em quadrinhos, em páginas simples, mas a maioria das 29 imagens totais do livro, em página dupla. 0 personagem principal é um gato preto que circula por diferentes cenas, e suas ações características de felinos despertam a curiosidade das pessoas que cruzam com ele. Por fim, o gato encontra uma menina lendo em um parque e se aconchega em seu colo. Nesse livro, duas personagens negras aparecem em duas cenas distintas, a primeira delas, uma menina, que observa o gato junto a um grupo de pessoas, e depois um homem sentado em um banco de um parque alimentando pássaros (JUNQUEIRA; HADDAD, 2012, p. 11, 17), como é possível ver na Figura 3.

Figura 3 - Capa e miolo do livro 0 gato e a menina

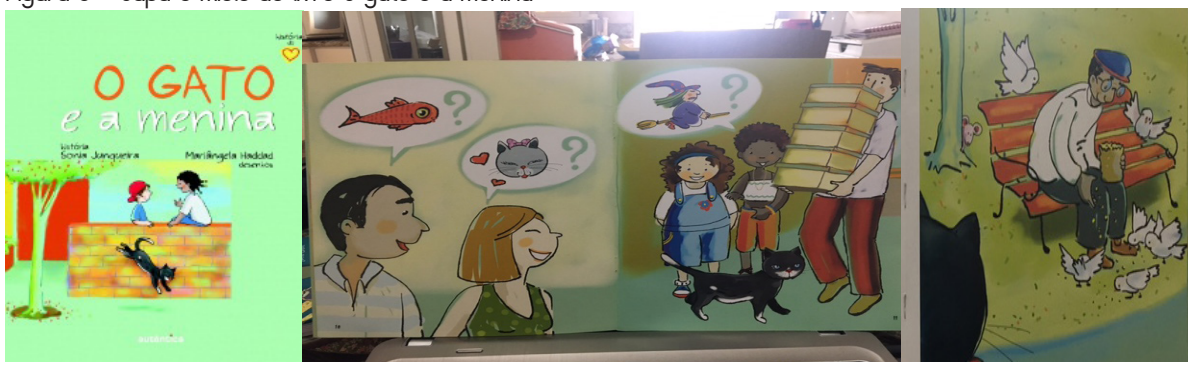

Fonte: os autores. 
Retomando um personagem que é citado pelos adultos para causar medo nas crianças, o livro Lá vem o homem do saco, de Regina Rennó (2013), tem formato quadrado, de $20 \mathrm{~cm} X 20 \mathrm{~cm}$. As imagens em preto e branco, que dão o tom de suspense da narrativa, vão sendo progressivamente coloridas nas três últimas imagens, que vão tomando, aos poucos, o espaço da página. A narrativa inicia quando um homem com um saco nas costas, caminhando pelas ruas de uma cidade antiga, aguça a curiosidade e o medo de crianças, que o observam das janelas de diferentes construções, até que descobrem que o que ele carregava dentro do saco era um acordeão e que a música poderia tornar o dia mais divertido. 0 livro tem guardas pretas e 24 páginas com 11 imagens que compõem a narrativa, e é somente na última imagem, em uma página simples, que é mostrada uma personagem negra: uma das crianças que está em meio a um grupo de outras crianças junto ao homem que toca seu acordeão (Figura 4).

Figura 4 - Capa e miolo do livro Lá vem o homem do saco

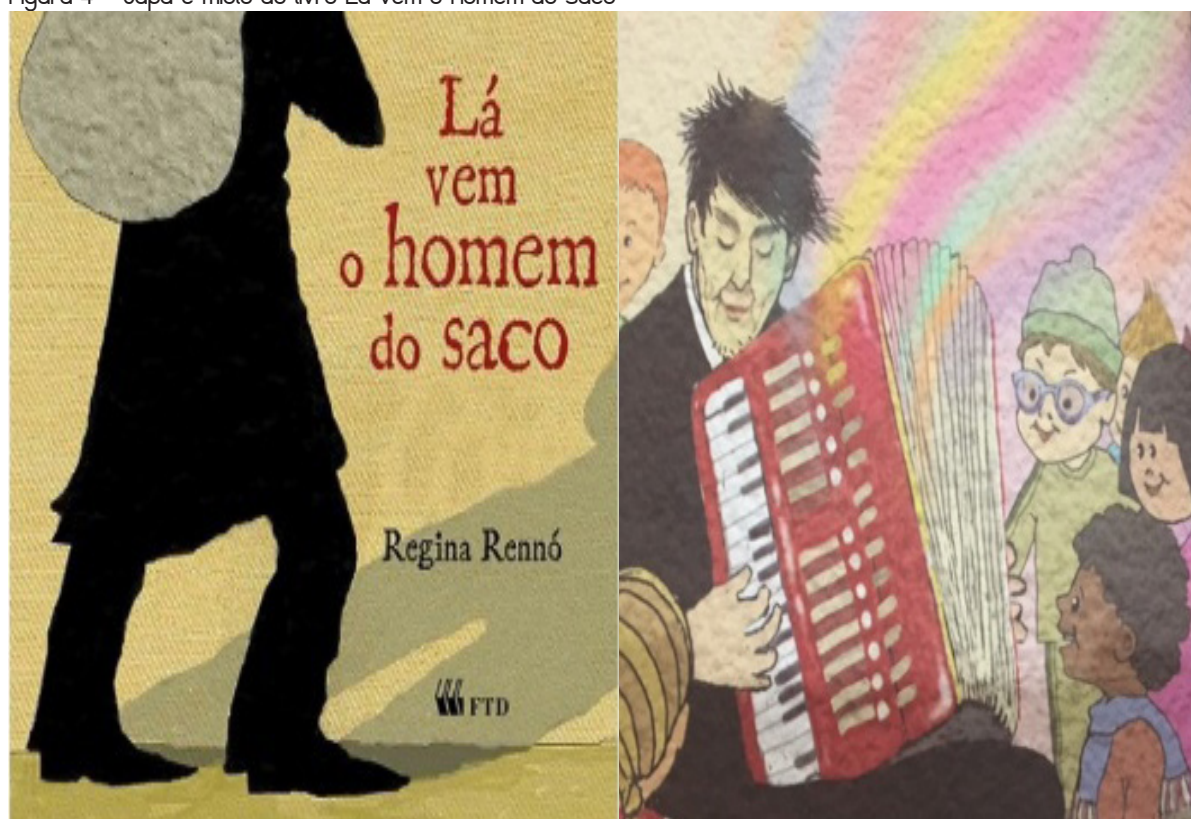

Fonte: os autores.

Voa pipa, voa, livro de Regina Rennó (2011), tem formato quadrado e mede 21,5 cm X 21,5 cm. Composto por 36 páginas, possui 23 imagens que contam a narrativa, 10 delas dispostas em páginas duplas, sem margens, e outras 13 em páginas simples, com molduras. A história é contada pelas imagens de um menino que, ao se mudar para um novo lugar, brinca na rua sozinho com uma bola e depois com um pião, enquanto isso as outras crianças 
ocupam seu tempo assistindo televisão, jogando videogame, falando ao celular ou em frente a um computador, ou seja, cada um dentro de sua casa. Até quando observam uma pipa, construída pelo menino que brincava sozinho, voando através de suas janelas, como um convite para que brincassem todos juntos. 0 personagem negro aparece em diferentes momentos da narrativa, em duas situações distintas, primeiramente sozinho dentro de seu apartamento (RENNÓ, 2011, p. 15, 21) (Figura 5) e em depois junto com os outros meninos, em situações de brincadeira (RENNÓ, 2011, p. 24-25, 27, 29, 31-35).

Figura 5 - Capa e miolo do livro Voa pipa, voo

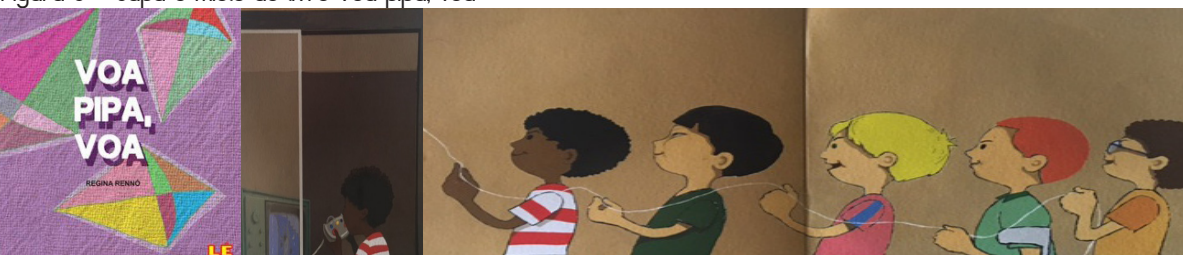

Fonte: os autores.

\section{AS PERSONAGENS NEGRAS INSERIDAS NO CONTEXTO DA NARRATIUA COM PAPEL ATIUO}

Outros oito livros trazem personagens negras que participam da narrativa, sendo que quatro elas participam da ação, mas não são protagonistas, e quatro são protagonistas.

0 tema do livro Brinquedos, de André Neves (2009), versa sobre as crianças que trabalham em um lixão e vivem em situação de risco. A narrativa acontece no decorrer de 32 páginas, dentre as quais algumas imagens ocupam páginas únicas e outras, páginas duplas. Possui $22 \mathrm{~cm} \mathrm{X} 20 \mathrm{~cm}$. A narrativa apresenta quatro diferentes crianças e sua relação com um palhaço e uma boneca de brinquedo. As primeiras duas crianças, um menino e uma menina, ganham os brinquedos e os jogam no lixo assim que se cansam deles. Esses brinquedos são encaminhados a um depósito, um lixão a céu aberto, até que, encontrados por outras duas crianças, um menino branco e uma menina negra, que aparecem a partir da página 19 até o final da narrativa, que recolhem do lixo artigos que lhes garantem um meio de sobrevivência, são costurados, cuidados e transformados em novos brinquedos (Figura 6). 
Figura 6 - Capa e miolo do livro Brinquedos

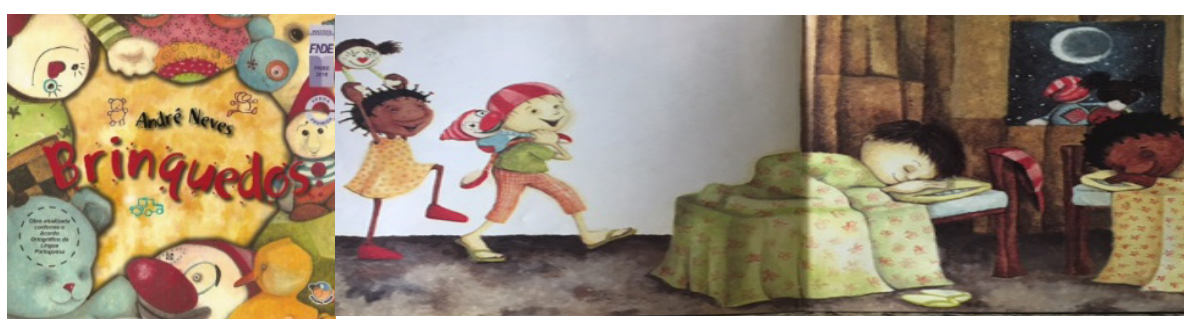

Fonte: os autores.

0 livro Brinquedos faz uma crítica de forma reflexiva sobre o trabalho infantil, bem como sobre o protagonismo da menina negra que está inserida nesse contexto, demonstrando que a cor da pele determina os espaços que as crianças em vulnerabilidade social ocupam, já que as duas crianças no início da narrativa são brancas e circundam em espaço abastado, uma casa cercada de objetos, enquanto uma das crianças que trabalha no lixão é negra.

0 livro 0 mistério da Caixa Vermelha tem formato quadrado e mede $21 \mathrm{~cm} \times 21$ $\mathrm{cm}$. De autoria de Semíramis Paterno (2008), 24 páginas formam a narrativa de 18 imagens: três delas em páginas duplas, e as restantes em páginas simples. Todas as imagens, com desenhos de traços realistas, são emolduradas por uma linha vermelha, com exceção da última, que ocupa todo o espaço da página. As imagens da narrativa contam as reações de diferentes pessoas quando encontram uma caixa vermelha em seu caminho: um homem de terno que, ao abrir a caixa, fica bravo; uma mulher passeando com seu cachorro que se sente feliz com a surpresa; um homem idoso que abre a caixa e se surpreende com o que descobre; e, por fim, um menino negro (PATERNO, 2008, p. 20, 23) que, ao abrir a caixa, brinca com as expressões em seu rosto e ao final descobre que o que tinha dentro dela era um espelho. 0 menino torna-se a principal personagem do livro, já que é ele quem desvenda o mistério proposto pela narrativa (Figura 7).

Figura 7 - Capa e miolo do livro 0 mistério da caixa vermelha
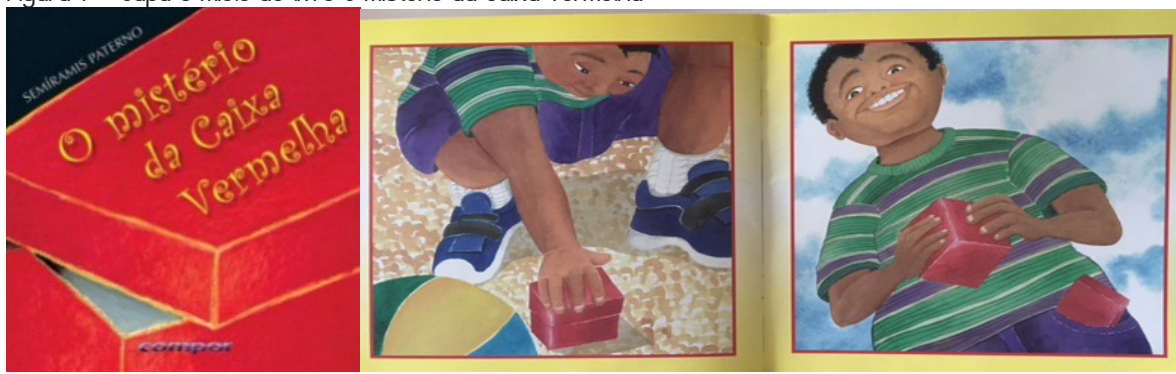

Fonte: os autores. 
0 livro de Regina Rennó (2009b), Viagem a vapor, tem formato quadrado, com 20 $\mathrm{cm} X 20 \mathrm{~cm}$ e possui 24 páginas que constroem uma narrativa em 17 imagens, compostas por fotografias coloridas e desenhos com aspectos animados, todas com margens brancas que as emolduram. No decorrer da história, as imagens variam a organização na página, algumas em páginas duplas, outras em páginas simples. Dentro de um barco que navega por um rio estão duas crianças, uma menina branca e um menino negro (RENNÓ, 2009b, p. 7), que durante o passeio se aventuram encontrando animais selvagens (jacaré e hipopótamo), desembarcam do barco e exploram um castelo, onde encontram um dragão e caminham por uma floresta com outros animais selvagens, como o leão, o elefante e a onça pintada. Retornam ao barco, e a história termina quando uma imagem mostra as duas crianças protagonistas da narrativa brincando com uma bacia com água e um pequeno barco de brinquedo, cercados de animais de brinquedo. Duas são as crianças protagonistas dessa narrativa, uma delas é um menino negro, que, na maioria das cenas, é mostrado conduzindo o barco que leva as crianças para a aventura da história (Figura 8).

Figura 8 - Capa e miolo do livro Viagem a vapor

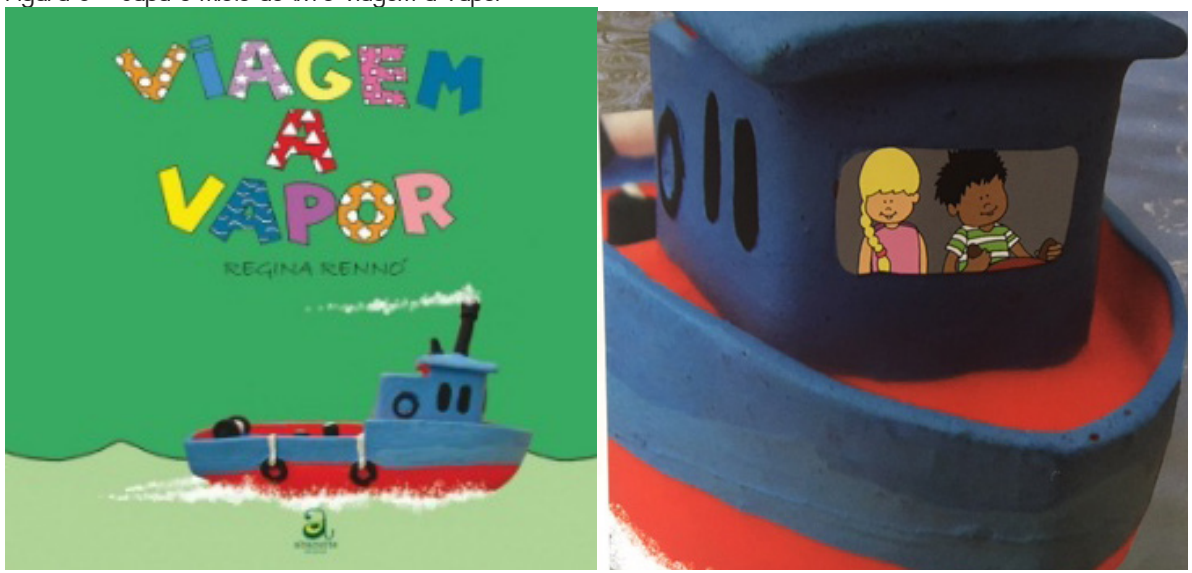

Fonte: os autores.

De dupla autoria, o livro 0 menino e o peixinho, de Sonia Junqueira e Mariângela Haddad (JUNQUEIRA; HADDAD, 2013), possui 32 páginas, de formato retangular e vertical, medindo $21 \mathrm{~cm} \mathrm{X} 24 \mathrm{~cm}$, e é contada a sequência de 18 imagens com características animadas, algumas delas organizadas em páginas duplas sem margens, outras em páginas simples com uma margem lateral de cor roxa. Na narrativa, uma professora surpreende as crianças de sua turma com uma mesa coberta com um pano. Embaixo dele havia sacos plásticos com 
diversos peixes coloridos, e cada criança podia escolher o peixe que quisesse. No entanto, apenas um peixe não é tão colorido e interessante como os demais, e é assim rejeitado por quase todas crianças, exceto por um menino, que troca o que havia escolhido pelo peixe cinza que havia restado, que era de outro colega. A partir daí, a narrativa desenrola-se para explorar a convivência cotidiana entre o menino e o peixe cinza, entre os momentos de cuidado com o pequeno animal até os momentos de diversão entre os dois: as histórias que o menino conta ao peixe, as fotografias que tiram juntos e as aventuras que o menino imagina (Figura 9).

Figura 9 - Capa e miolo do livro 0 menino e o peixinho

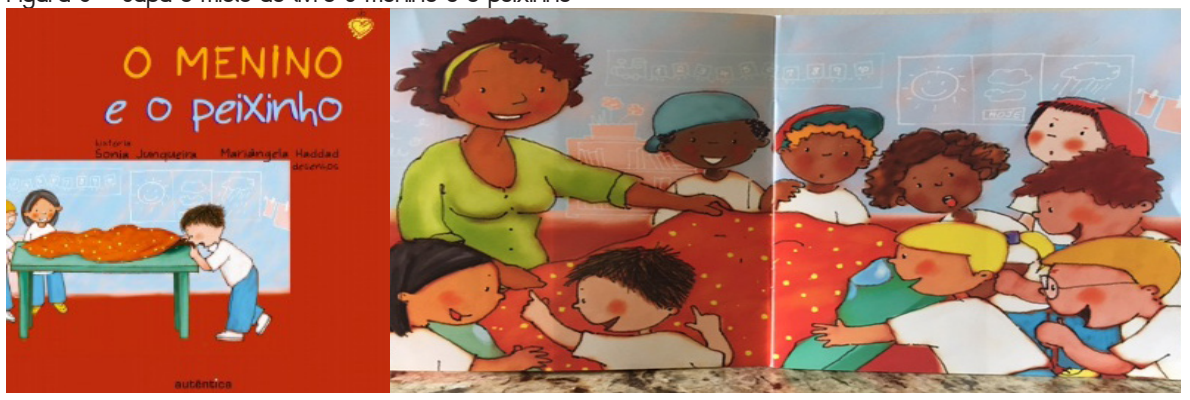

Fonte: os autores.

Entre os livros analisados nessa categoria, este é o que tem a maior quantidade de personagens negras: a professora e três crianças, uma menina e dois meninos, aparecendo nas páginas iniciais da narrativa, nos momentos em que as crianças e a professora aparecem coletivamente.

\section{PERSONAGENS NEGRAS COMO PROTAGONISTAS}

Apresentamos nesta seção as quatro narrativas que focalizam as personagens negras como protagonistas: Bem me quero, bem me querem, de Regina Rennó (2009a), 0 almoço, de Mario Vale (1987), Mar de sonhos, de Dennis Nolan (2012), e Quando os tam-tans fazem tum-tum, de lvan Zigg (2015), buscando elencar como essa apresentação se efetiva.

0 livro Bem me quero, bem me querem, de autoria de Regina Rennó (2009a), possui 20 páginas em forma de quadrado, medindo $21 \mathrm{~cm} \mathrm{X} 21 \mathrm{~cm}$. São 17 imagens que compõem a narrativa, mesclando fotografias em preto e branco e desenhos de personagens com características animadas; 16 das imagens estão organizadas em páginas simples, enquanto 
a imagem central do livro ocupa o espaço de página dupla. A narrativa conta a história de quatro crianças, duas meninas e dois meninos, as quais, uma a uma, vão se juntando e acompanham um menino em uma caminhada até a porta de um hospital. Uma das crianças é cega, conduzida por um cão-guia, e outra é cadeirante. A caminhada serviria para que o menino negro e seus amigos fossem até o hospital para visitar seus pais e os bebês, um casal de gêmeos, que acabaram de nascer (Figura 10). 0 protagonismo da narrativa é da família e do menino negro, que aparece em todas as cenas da história.

Figura 10 - Capa e miolo do livro Bem me querem, bem me quero

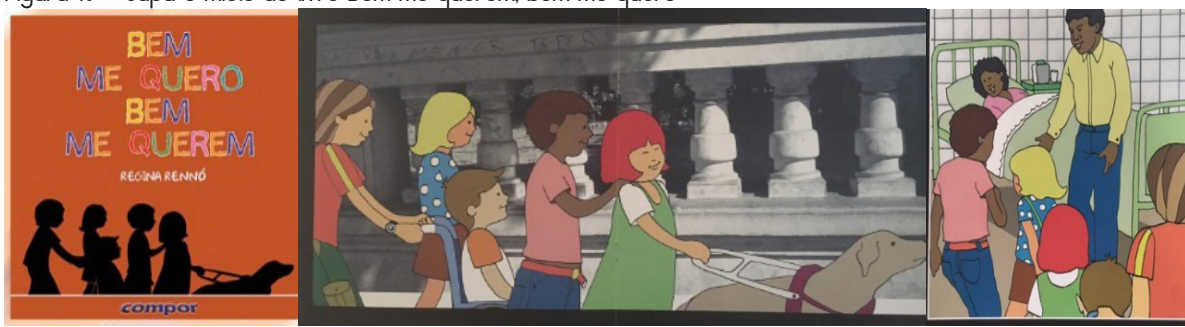

Fonte: os autores.

Mario Vale (1987) é o autor de 0 almoço. Um livro de grandes proporções, de forma quadrada, com $30 \mathrm{~cm}$ X $30 \mathrm{~cm}$. A narrativa é composta por oito páginas, e as imagens são emolduradas e construídas a partir de recortes e colagem de papel de cores vivas em cenários, que, posteriormente, são fotografados. A narrativa se realiza pela movimentação de um homem negro que, ao encontrar uma toca, retira de dentro dela um coelho e o leva para casa, movimenta-se pela cozinha, primeiramente acendendo a boca de um fogão e colocando uma panela para esquentar, e depois levando a panela ao encontro de uma mesa arrumada para a refeição. Ao final da história, dentro da panela, cenouras cozidas que serão divididas com o coelho, que ocupa um lugar na outra ponta de mesa.

0 texto, carregado de nonsense, provoca no leitor uma quebra de expectativas construídas pela cena: um homem que encontra um coelho e o leva para casa e prepara a comida faz com que se preveja que o coelho seria a refeição, mas essa hipótese se desfaz e a ele é servida a refeição. A personagem negra, um homem de roupas coloridas, com o cabelo verde encaracolado e lábios exageradamente grandes, é representada de forma negativa (Figura 11). 
Figura 1 - Capa e miolo do livro 0 almoço

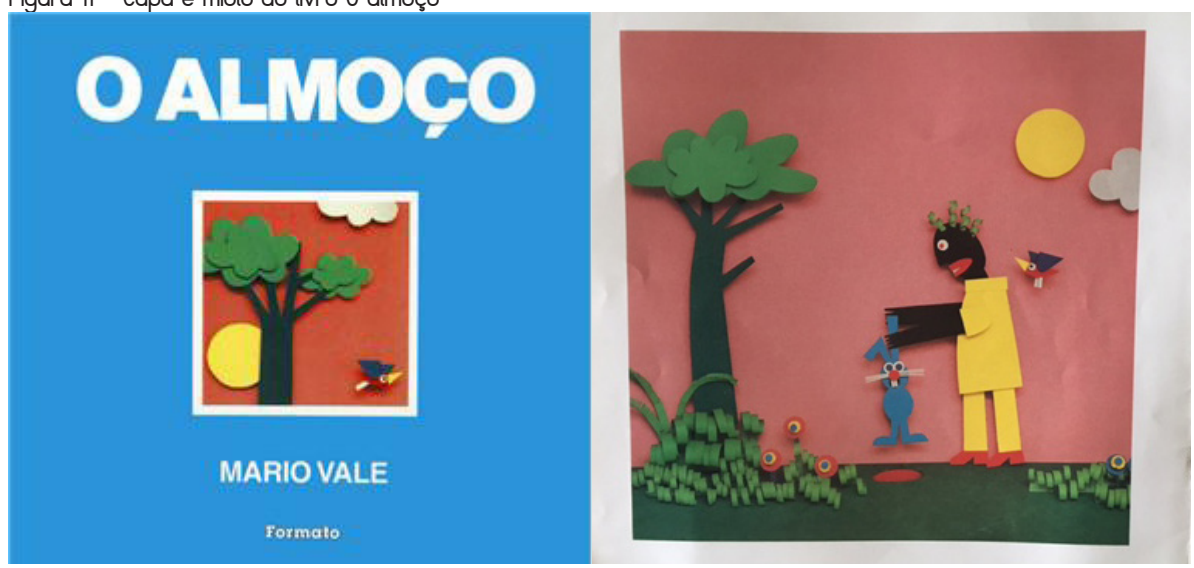

Fonte: os autores.

Mar de sonhos é um livro de Dennis Nolan (2012), que tem formato retangular horizontal e mede $24 \mathrm{~cm}$ X $18 \mathrm{~cm}$. A narrativa imagética versa sobre uma menina negra que constrói na praia um castelo de areia, e quando a noite chega o castelo se desfaz, tomado pelas ondas da maré que subiu, obrigando a uma família que nele morava a deixar a segurança do lar para enfrentar a grandeza de um oceano. Deparando-se com aventuras e guiados por uma gaivota que os acompanha em todas as ações, buscam por um lugar seguro para ficar. Quando amanhece, a mesma menina retorna à praia e constrói um novo castelo de areia, que novamente é invadido pela água. 0 livro tem 40 páginas e 21 imagens que compõem a narrativa, duas delas, a primeira e a última, em páginas simples, e as outras 18 imagens em páginas duplas sem nenhuma margem que as delimitem. Com desenhos com traços realistas, a história circular convida o leitor a novamente iniciar a viagem das personagens.

A menina negra é retratada de forma positiva, sem traços estereotipados ou exageros na representação, as imagens compõem uma narrativa em que o cotidiano contemporâneo se sobressai e a infância acena como uma possibilidade repleta de meninice, nos gestos brincantes da personagem (Figura १२).

Figura 12 - Capa e miolo do livro Mar de sonhos

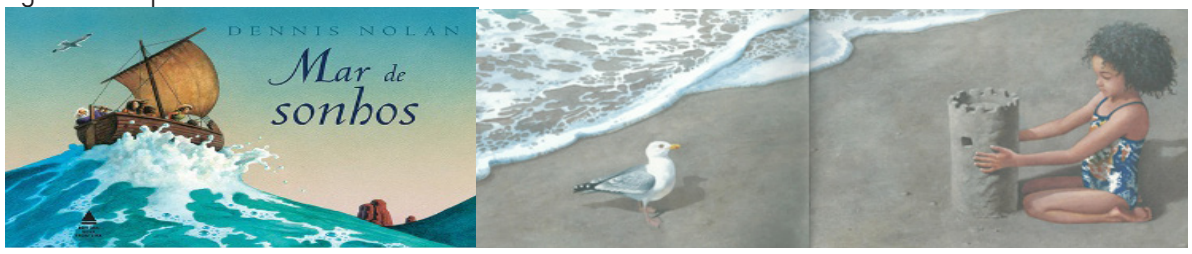

Fonte: os autores. 
Quando os tam-tans fazem tum-tum é um livro de Ivan Zigg (2013), de formato quadrado, com $24 \mathrm{~cm} \mathrm{X} 24 \mathrm{~cm}$; tem 34 páginas, com 17 imagens com traços de desenhos animados, uma delas está disposta como uma história em quadrinhos e ao lado dela uma imagem em página simples, outras cinco também estão arranjadas em páginas simples, e o restante delas em páginas duplas. Um palhaço negro, acostumado a fazer rir suas plateias, depara-se com uma situação diferente, uma plateia formada de máscaras africanas de expressões cerradas. 0 palhaço, então, usa de muitas artimanhas para causar o riso, e só consegue fazer isso quando seu nariz de palhaço é retirado dele e usado por uma das máscaras.

Figura 13 - Capa e miolo do livro Quando os tam-tans fazem tum-tum

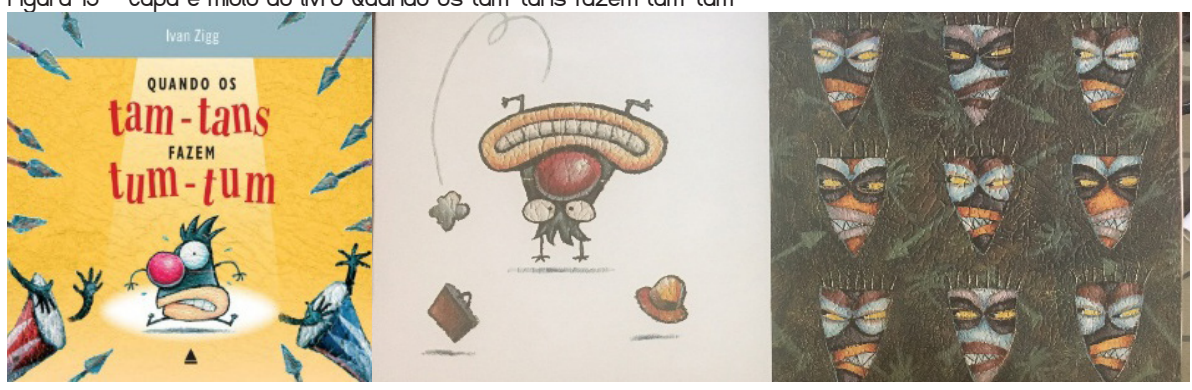

Fonte: os autores.

Este é o único título que traz elementos associados à cultura africana: os tambores (tam-tans), as lanças e a máscaras; os dois primeiros aparecem já na capa, reproduzindo partes de uma imagem interna, e as máscaras que aparecem internamente aparecem de modo negativo, como repressão, mesmo que a intenção seja provocar o riso, quando uma das máscaras rouba o nariz do palhaço. 0 palhaço, o personagem negro protagonista da narrativa, é representado com lábios exagerados, marcando o estereótipo da imagem do negro.

\section{ALGUNS ENCONTROS E DESENCONTROS}

0 PNBE, sem sombra de dúvidas, trouxe para as bibliotecas escolares da Educação Básica um número considerável de títulos de diferentes gêneros, inclusive o livro de imagem que, independente da etapa de ensino - leitores e não leitores - aproxima da leitura imagética 
e da estrutura narrativa, possibilitando um alargamento da constituição leitora, isto é, não lemos só as palavras.

No entanto, a representação de personagens negras nos livros infantis ainda não é uma recorrência e quando aparecem, nem sempre se efetivam de forma positiva. 0s 13 títulos aqui analisados, mesmo que brevemente, trazem alguns pontos para reflexão: em nenhum dos títulos a representação das personagens negras ocorre pela representação da escravização, tema ausente das narrativas imagéticas aqui analisadas, por outro lado, somente trazem o protagonismo negro.

Em 0 almoço, de Mário Vale, a personagem adulta compõe uma história insólita - a amizade entre um homem e um coelho, e embora tenha aspectos positivos no seu enredo, representa a personagem negra de forma estereotipada com lábios grandes e avermelhados. Mar de sonhos, de Dennis Dolan, é, sem sombra de dúvidas, o título que melhor representa as características negras da personagem, sem estereotipá-las. Um único título, Quando os tamtans fazem tum-tum, de lvan Zigg, traz elementos característicos da cultura africana, porém é trabalhado de modo a não haver identificação do leitor com esses elementos, já que oprimem outra personagem pela violação do que the marca, no caso o nariz de palhaço.

Pela síntese dos três títulos apresentados em que as personagens são protagonistas, constata-se que a prerrogativa de protagonismo não qualifica por si só a representação, como no título Quando os tam-tans fazem tum-tum, em que a estilização na caracterização da personagem mais confunde do que agrega um olhar positivo e realista aos elementos da cultura africana.

0 livro de imagem, enquanto narrativa encharcada de ficcionalidade, carrega consigo, como os outros gêneros literários, a possibilidade de apresentar ao leitor a reinvenção de mundo, um mundo vivido e um mundo sonhado, um mundo dado e um mundo a construir. Revestido da subjetividade da qual o pacto ficcional é portador, o livro de imagem pode confluir para práticas antirracistas na educação das relações étnico-raciais, e para isso precisaríamos de mais títulos como Mar de sonhos, de Dennis Dolan.

\section{REFERÊNCIAS}

ABRAMOVICH, F. Literatura Infantil: gostosuras e bobices. São Paulo: Scipione, 1997.

ARAUJO, D. C. Literatura Infanto-Juvenil e Política Educacional: estratégias de racialização no Programa Nacional de Biblioteca da Escola (PNBE). 2015. 335 f. Tese (Doutorado em Educação) - Programa de Pós-Graduação em Educação, Universidade Federal do Paraná, Curitiba, 2015. Disponível em: http:// www.ppge.ufpr.br/teses\%20d2015/d2015_Debora\%20Cristina\%20de\%20Araujo.pdf Acesso em: 14 abr. 2017. 
ARAUJO, D. C. Relações raciais, discurso e literatura infanto-juvenil. 2010. 192 f. Dissertação (Mestrado) - Programa de Pós-Graduação em Educação, Universidade Federal do Paraná, Curitiba, 2010. Disponível em: http://www.ppge.ufpr.br/teses/M10_araujo.pdf. Acesso em: 14 abr. 2017.

BELMIRO, C. Livro de Imagens. In: CENTRO DE ALFABETIZAÇÃO, LEITURA E ESCRITA. Glossário Ceale: termos de alfabetização, leitura e escrita para educadores. Belo Horizonte: UFMG, 2017. Disponível em: http:// ceale.fae.ufmg.br/app/webroot/glossarioceale/verbetes/livro-de-imagens. Acesso em: ago. 2017.

BRASIL. Lei n. 9.394, de 20 de dezembro de 1996. Estabelece as diretrizes e bases da educação nacional. Diário Oficial da União, Brasília, DF, 23 dez. 1996.

BRASIL. Lei n. 10.639, de 9 de janeiro de 2003. Altera a Lei n 9.394, de 20 de dezembro de 1996, que estabelece as diretrizes e bases da educação nacional, para incluir no currículo oficial da Rede de Ensino a obrigatoriedade da temática «História e Cultura Afro-Brasileira», e dá outras providências. Diário Oficial da União, Brasília, DF, 10 jan. 2003.

BRASIL. Lei $n$. 11.645, de 10 de março de 2008. Altera a Lei n 9.394, de 20 de dezembro de 1996, modificada pela Lei $n^{\circ} 10.639$, de 9 de janeiro de 2003, que estabelece as diretrizes e bases da educação nacional, para incluir no currículo oficial da rede de ensino a obrigatoriedade da temática "História e Cultura Afro-Brasileira e Indígena". Diário Oficial da União, Brasília, DF, 11 mar. 2008.

BRASIL. Portaria Ministerial n. 584, de 28 de abril de 1997. Regulamenta a instituição do Programa Nacional Biblioteca da Escola. Diário Oficial da União, Brasilia, DF, 28 abr. 1997.

DEBUS, E. A temática da cultura africana e afro-brasileira na literatura para crianças e jovens. Florianópolis: NUP/CED/UFSC, 2017.

FERNANDES, C. R. D. Leitura, literatura infanto-juvenil e educação. Londrina: EDUEL, 2007.

FERREIRA, L. D. A personagem do conto infanto-juvenil brasileiro contemporâneo: uma análise a partir do PNBE/2005. 2008. 162 f. Dissertação (Mestrado) - Programa de Pós-Graduação em Literatura Brasileira. Universidade de Brasília. Brasilia, DF, 2008.

IACOCCA, M. 0 encontro. Curitiba: Positivo, 2008.

JUNQUEIRA, S.; HADDAD, M. 0 gato e a menina. Belo Horizonte: Autêntica, 2012.

JUNQUEIRA, S.; HADDAD, M. 0 menino e o peixinho. Belo Horizonte: Autêntica, 2013.

LOPES, N. R. Programa Nacional Biblioteca da Escola (PNBE) 2010: personagens negros como protagonistas e a construção da identidade étnico-racial. 2012. 156 f. Dissertação (Mestrado) - Programa de Pós-Graduação em Educação da Faculdade de Filosofia e Ciências, Universidade Estadual Paulista Júlio de Mesquita, Campus Marilia, São Paulo, 2012.

NEVES, A. Brinquedos. São Paulo: Mundo mirim, 2009. 
NOLAN, D. Mar de sonhos. Rio de Janeiro: Nova Fronteira, 2012.

OLIVEIRA, V. C. S. Educação das relações étnico-raciais e estratégias ideológicas no acervo do PNBE 2008 para educação infantil. 2010. 190 f. Dissertação (Mestrado) - Programa de Pós-Graduação em Educação, Universidade Federal do Paraná, 2010. Disponível em: http://www.ppge.ufpr.br/teses/ M11_Verediane\%20Cintia\%20de\%20Souza\%200liveira.pdf. Acesso em: 14 abr. 2017.

PAIVA, A. (org.). Literatura fora da caixa: o PNBE na escola - distribuição, circulação e leitura. São Paulo: Ed. Unesp, 2012.

PATERNO, S. 0 mistério da Caixa Vermelha. Belo Horizonte: Compor, 2008.

RENNÓ, R. 0 presente que veio do céu. Belo Horizonte: Compor, 2007.

RENNÓ, R. Bem me quero bem me querem. Belo Horizonte: Compor, 2009a.

RENNÓ, R. Viagem a vapor. Belo Horizonte: Abacatte, 2009b.

RENNÓ, R. Voa Pipa, voa. Belo Horizonte: Lê, 2011.

RENNÓ, R. Lá vem o homem do saco. São Paulo: FTD, 2013.

REYES, Y. A casa imaginária: leitura e literatura na primeira infância. Tradução: Márcia Frazão e Ronaldo Periassu. São Paulo: Global, 2010.

SPENGLER, M. L. P. Alçando voos entre livros de imagem: o acervo do PNBE para a educação infantil. 2017. 213 f. Tese (Doutorado em Educação) - Programa de Pós-Graduação em Educação, Universidade Federal de Santa Catarina, Florianópolis, 2017.

VALE, M. 0 almoço. Belo Horizonte: Formato editorial, 1987.

VENÂNCIO, A. C. L. Literatura infanto-juvenil e diversidade. Dissertação (Mestrado) - Programa de Pós-Graduação em Educação, Universidade Federal do Paraná, Curitiba, 2009. Disponivel em: http://www. ppge.ufpr.br/teses/M09_venancio2.pdf. Acesso em: 14 abr. 2017.

ZIGG, I. Quando os tam-tans fazem tum-tum. Rio de Janeiro: Nova Fronteira, 2013.

Endereços para correspondência: Rua Itajaí, 860, Bairro Sete de Setembro, 89115-001, Gaspar, Santa Catarina, Brasil; elianedebus@hotmail.com 